\title{
CALENDÁRIO ETNOBIOLÓGICO DO CARANGUEJO-UÇÁ Ucides cordatus (LINNAEUS, 1763) (BRACHYURA: OCYPODIDAE) COM BASE NOS CONHECIMENTOS DOS CATADORES DE CARANGUEJO DO ESTUÁRIO DO RIO ITANHAÉM - SP
}

\author{
Matsunaga, A.M.F. ${ }^{1,2,}$; Barbi, F.V. ${ }^{1,2}$ \& Pinheiro, M.A.A. ${ }^{1,2}$ \\ ${ }^{1}$ Universidade Estadual Paulista (UNESP), Instituto de Biociências (IB), Campus do Litoral Paulista (CLP), \\ Laboratório de Biologia da Conservação de Crustáceos (LBC/CRUSTA), São Vicente (SP). \\ ${ }_{2}^{2}$ Programa de Pós-Graduação em Biodiversidade Aquática, Universidade Estadual Paulista (UNESP), \\ Instituto de Biociências (IB), Campus do Litoral Paulista (CLP). \\ *Autor correspondente: barbifevargas@gmail.com
}

\begin{abstract}
A Etnobiologia é uma ciência que auxilia a melhor compreensão dos processos de investigação que envolvem o homem e a natureza, trazendo informações importantes ao manejo e gestão dos ecossistemas e recursos naturais. O caranguejo-uçá é um crustáceo decápode endêmico de manguezais, associado à sua vegetação arbórea e distribuído por todo o litoral brasileiro. Desempenha importante papel nos processos ecossistêmicos, participando da bioturbação dos sedimentos e do fluxo da matéria orgânica e energia, afetando toda a cadeia trófica e o equilíbrio do ecossistema manguezal. O presente estudo visa levantar conhecimentos etnobiológicos dos catadores de caranguejo do Estuário do Rio Itanhaém (SP), relativos ao crescimento (muda) e reprodução de Ucides cordatus, bem como sua correspondência aos dados científicos disponíveis na literatura. Os catadores de caranguejo conhecidos, bem como outros indicados (técnica snow ball) foram indagados quanto a ocorrência mensal, durante um ano, de estágios biológicos do caranguejo-uçá, em especial sobre a época de crescimento (incidência de muda e do "caranguejo-leite"), bem como a época reprodutiva ("andada", briga entre machos, cópula e registro de fêmeas ovígeras), nos manguezais do Rio Itanhaém/SP. Além disso, foi realizado um levantamento bibliográfico sobre a ocorrência destes eventos biológicos, com avaliação de sua incidência mensal, que foi confrontado aos dados oriundos do conhecimento etnobiológico. Foram entrevistados nove catadores de caranguejo que atuam nos manguezais do Rio Itanhaém, superando em 180\% o número daqueles registrados pela colônia de pescadores para esta área. O período de muda indicado pelos catadores (julho a dezembro) foi mais amplo do que o constatado na literatura (setembro e outubro), mas com associação significativa da incidência de muda e do caranguejo-leite $(r=0,87 ; p<0,05)$, e correspondência de $75 \%$ ao conhecimento científico. Já os estágios biológicos relacionados à reprodução, apresentaram correlação fortemente positiva e significativa entre si $(r \geq 0,92 ; p<0,05), 72 \%$ dos quais confirmados cientificamente. De modo geral, os resultados etnobiológicos obtidos totalizaram $73 \%$ das informações previamente obtidas pelo método científico, reforçando a relevância e acuidade do conhecimento tradicional por percepção humana na interpretação de dados da natureza.
\end{abstract}

Palavras-chave: caranguejo, ciclo de vida, entrevista, etnobiologia, manguezal. 